لمستحداث ونمومزارع الكالسمن قلع السقلن ولاورق الفلفية لنبل الخرنوب Prosopis farcta L.

\author{
* هiاعسعيد الصالح \\ رناطارق يحيى \\ جلمعة علوم الملية العلوم \\ جلمعة علوم الملية العلوم \\ جلمعة علوم الملية العلوم \\ *Email: $\underline{\text { h.alsalih@yahoo.co.uk }}$
}

(تاريخ الإستلم 8 / 4 / 2013 ؛ تاريخ القبول 27 / 5 / 2013)

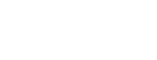

تمكنت الدرلسة الحالية من ايجاد الظروف المثل للاستحداث ونمو كاللس قطعس يقلن والأوراق الفلقي ة

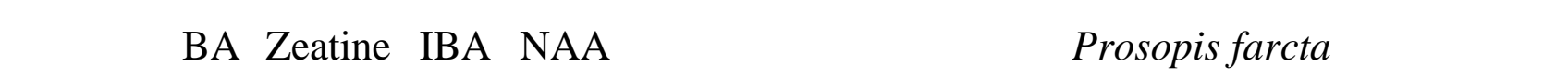

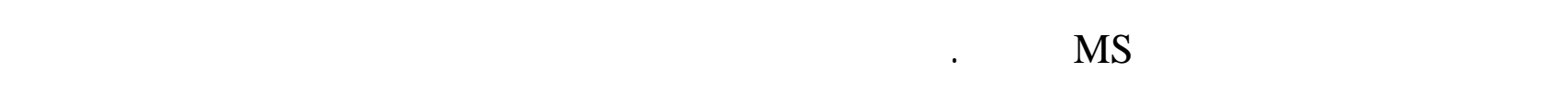

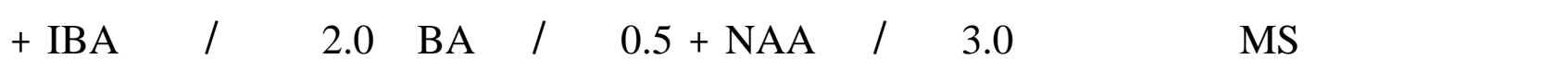

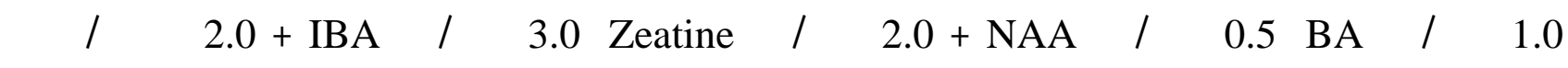

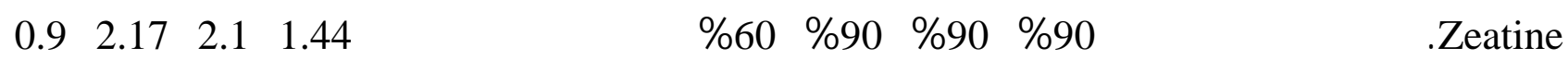

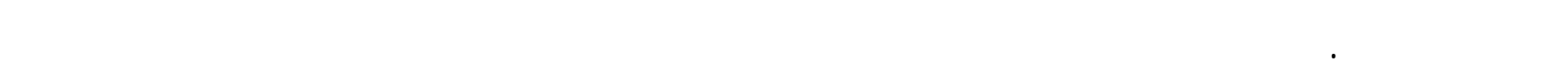

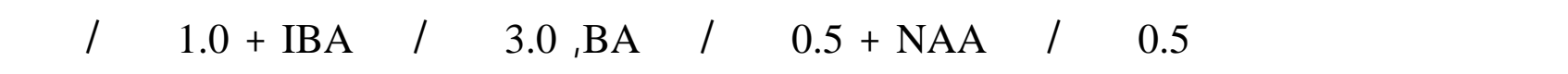

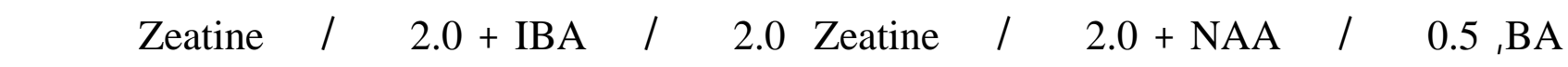

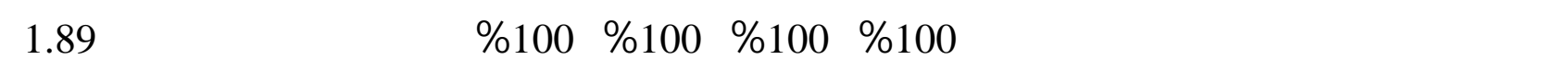

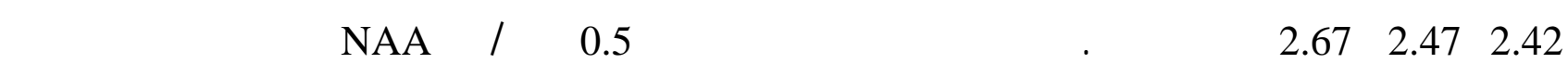

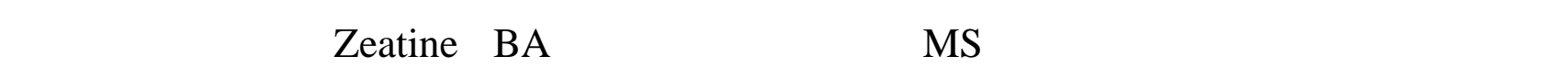
لستحداث الكالس والوزن الطري. في حين فشلت التطع النباتية جميعها في ققائها حية عند زراعتها على وسط MSO الصلب. الكاملت الدالة: نببت الخرنوب، مظملت النمو النباتية، مزارع الكالس. 


$$
\text { رناطارق يحيى و هناعسعيد الصالح }
$$

\title{
Induction of Callus Cultures from Stems and Cotyledonary Leaves of Prosopis farcta L. by Using some Plant Growth Regulators
}

\author{
Rana T. Yahya \\ Hanaa S. Al-Salih \\ Department of Biology \\ College of Science \\ University of Mosul
}

\begin{abstract}
This study was capable to find the optimal conditions for callus initiation and growth from stems and cotyledonary leaves segments of Prosopis farcta, by using different concentrations of plant growth regulators NAA, IBA, Zeatine and BA alone or in an interaction between them in agar-solidified MS medium. The better media that encouraged callus induction from stem segments were those supplemented with $3.0 \mathrm{mg} / \mathrm{L} \mathrm{NAA}+0.5$ $\mathrm{mg} / \mathrm{L} \mathrm{BA}, 2.0 \mathrm{mg} / \mathrm{L} \mathrm{IBA}+1.0 \mathrm{mg} / \mathrm{L} \mathrm{BA}, 0.5 \mathrm{mg} / \mathrm{L} \mathrm{NAA}+2.0 \mathrm{mg} / \mathrm{L}$ Zeatine, $3.0 \mathrm{mg} / \mathrm{L}$ IBA $+2.0 \mathrm{mg} / \mathrm{L}$ Zeatine in which the induction percent reached $90 \%, 90 \%, 90 \%, 60 \%$ and fresh weight that reached up 1.44, 2.1, 2.17, 0.9 gm respectively. Whereas the better media that encouraged callus induction from cotyledonary leaves segments were those supplemented with $0.5 \mathrm{mg} / \mathrm{L} \mathrm{NAA}+0.5 \mathrm{mg} / \mathrm{L} \mathrm{BA}, 3.0 \mathrm{mg} / \mathrm{L} \mathrm{IBA}+0.1 \mathrm{mg} / \mathrm{L} \mathrm{BA}, 0.5 \mathrm{mg} / \mathrm{L} \mathrm{NAA}+2.0$ $\mathrm{mg} / \mathrm{L}$ Zeatine, $2.0 \mathrm{mg} / \mathrm{L} \mathrm{IBA}+2.0 \mathrm{mg} / \mathrm{L}$ Zeatine with callus induction percent reached to $100 \%, 100 \%, 100 \%, 100 \%$ and fresh weight average 1.89, 2.42, 2.47, 2.67 gm respectively. It is clear that $0.5 \mathrm{mg} / \mathrm{L} \mathrm{NAA}$ has an important role in callus initiation alone or with BA and Zeatine dependent on callus induction percent and its fresh weight.

On the other hand, the explants failed to continue in its viability when cultured on agar-solidified MSO medium.
\end{abstract}

Keywords: Prosopis farcta, plant growth regulators, callus cultures.

\section{الفقمة}

Kumer ) أحد نباتتات العائلة القولية Leguminaceae التي تضم 50 نوء

(and Singh, 2009

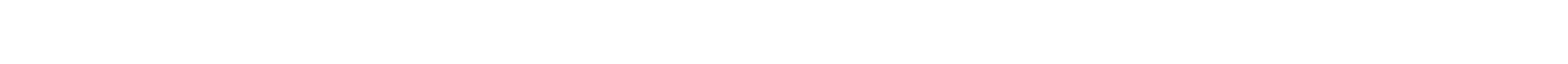
وهو نبلت حولي ينمو + بشكلش جيرات ق صيرة (Humberto et al., 2010; Asadollahi et al., 2010)

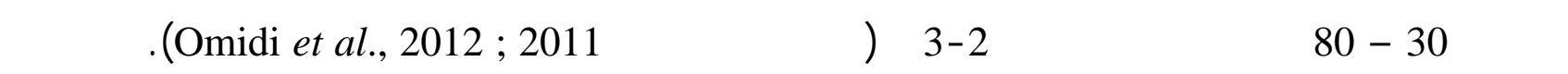

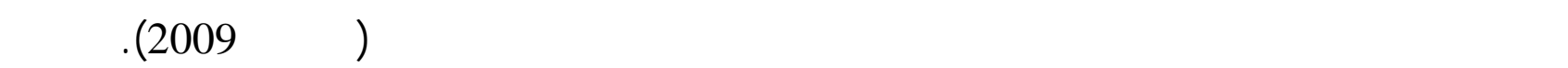

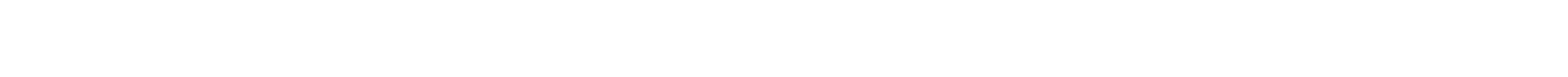
العديدمن العوالل (محمد وعمر، 1990) ومن اهمهامظملت النمو النباتية المضافة إل مى الوس ط الغ الغ ـذائي

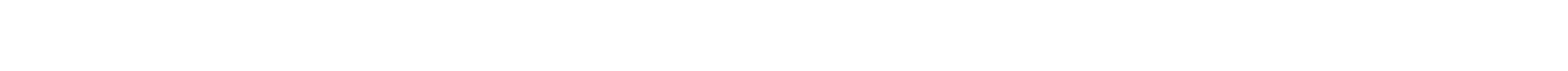




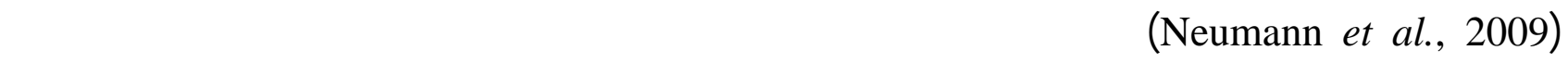

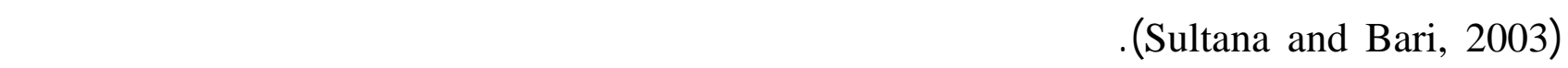
في الزراعة، نوع الفطعة النباتية ومصدرها، الظروف النمية بها، حهم وشكل الجزء النباتي, الوسط الغذائي

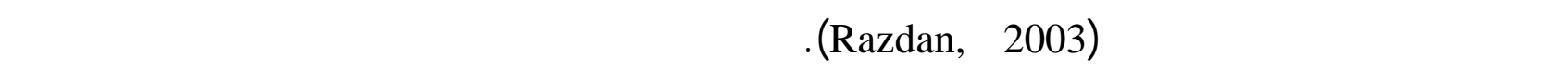

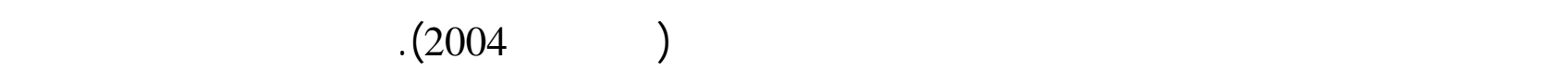

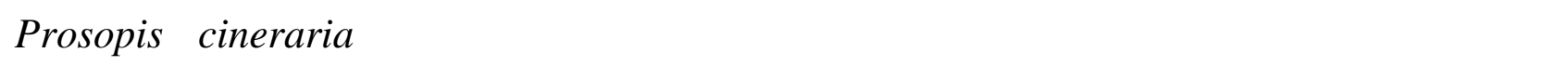
وإنتاج نباتت كلملة منها على ويط MS الصلب المدعم بتدلخلات مختلفة من مظملت النمو ( Kumer and .(Singh, 2009 هدفت الدرلسة الحالية اله لستحداث الكالس من قطع نبل Prosopis farcta لندرة الدرلست عليه ف ي

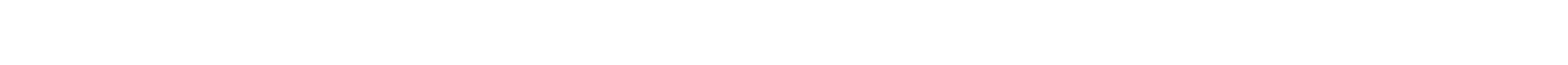
ترلكيز مظملت النمو الملائمة لذلك.

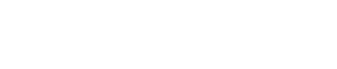

جمعت بذور نبباتت الخرنوب Prosopis farcta من الثمار الناضجة للنباتلت النمي ـةطبيعي أف في

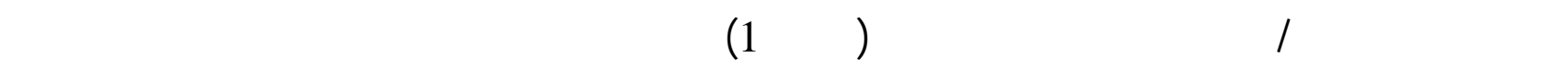
إنبات بذوره وبلغت 95 \% .

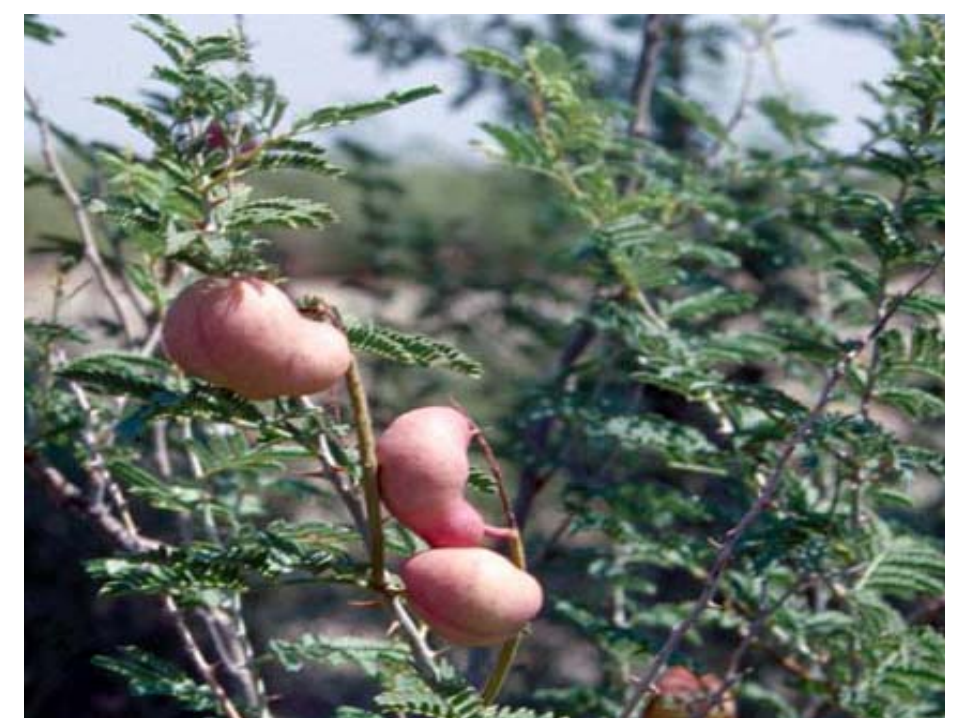

الشكل 1: نموذج من نبلتات الخرنوب Prosopis farcta النالي في البيئة

(www. alsirhan.com, 2002) 


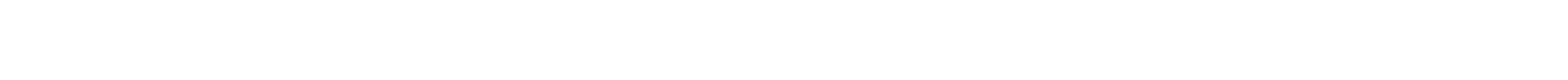

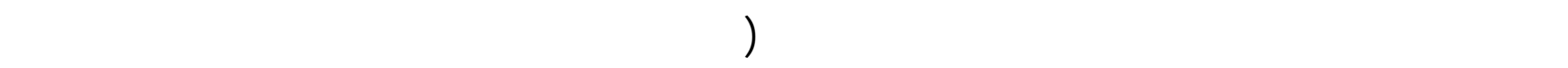

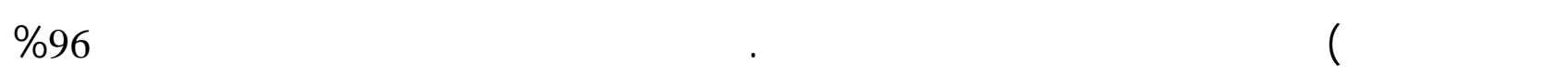

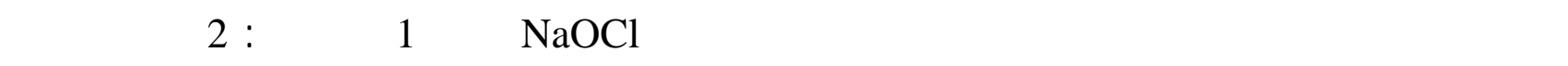

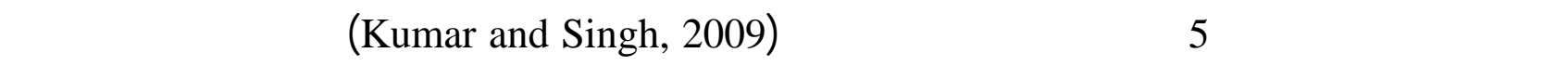

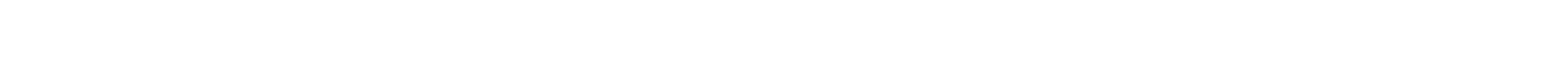

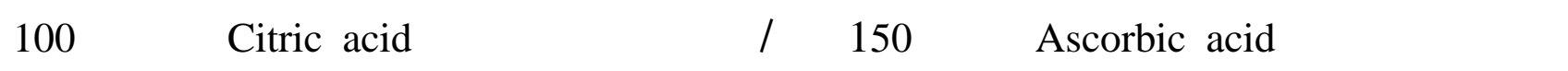

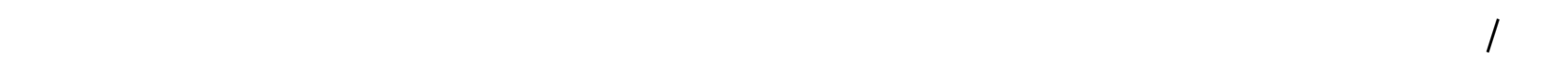

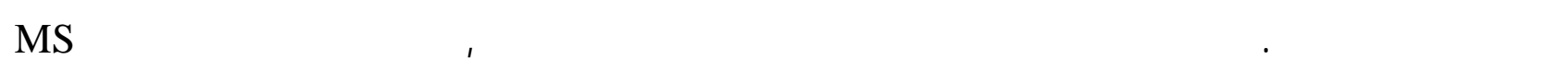

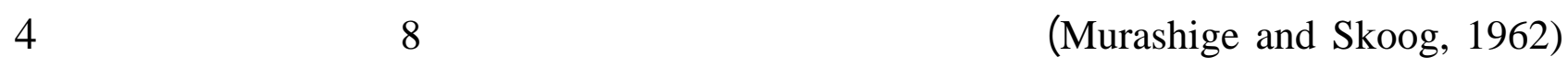
بذور لكل قنينة والحاوي على 5 غم/لترمن الفهم المنثط Activated Charcoal للمتصاص المواد الفينولية

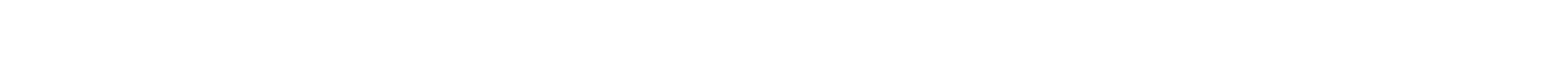

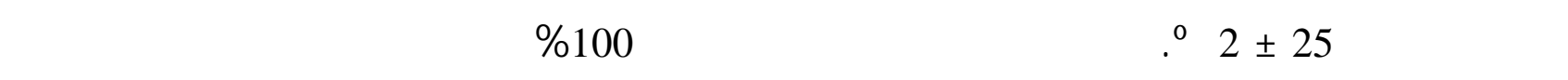

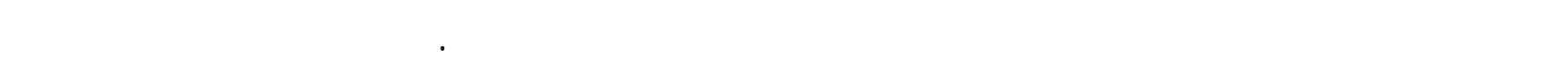
ظروف التعاقب الضوئي 16ساعة ضوء/8ساعلتظة لام بشة إضاءة 2000 لوكس وبذات درجة الح ـرارة أعلاه.

\section{لاستحداث الكالس من قاع السقلن ولأوراق الفلفية لبارلت نبلت الخرنوب:}

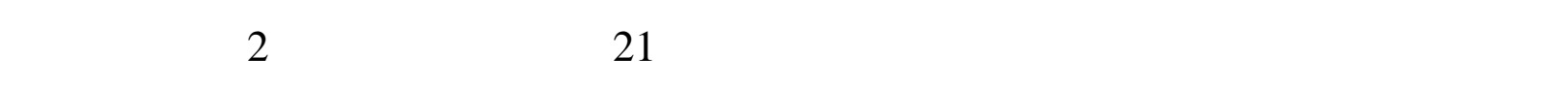

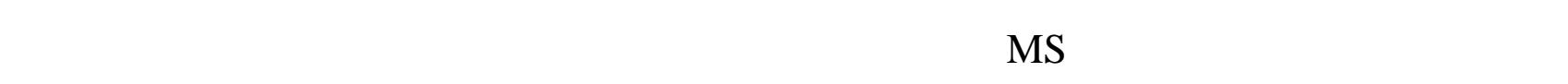

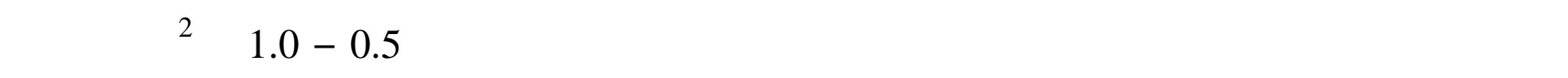
حوافها لغرض لستحداث الكالس منها ولستخمت فف الأوسيط الغذائية المزروعة عليها قطع للسيقلن.

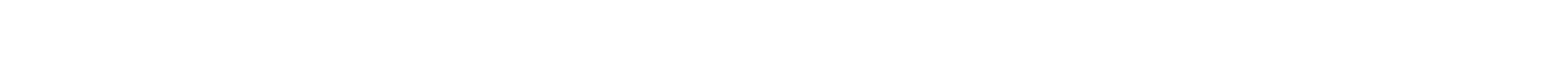

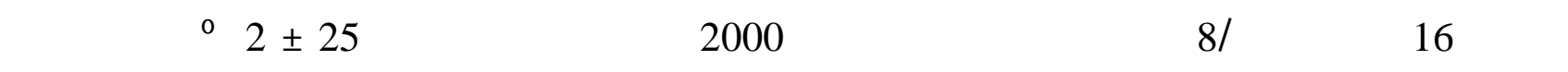

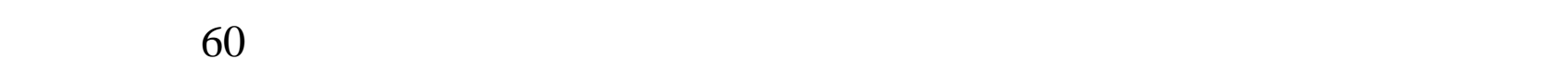


لستخدت ترلكيز من مظملت النمو المختلفة لبيلن كفائتها في لستحداث الك اللس ونم _و مت ـضمنة Indole butyric acid (IBA) Naphthaleneacetic acid NAA

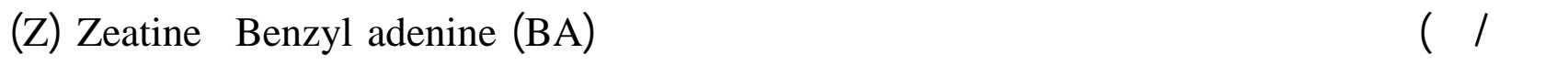

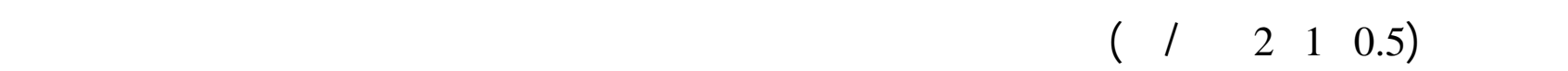
المقارنة بدون اضفافة مظملت النمو.

\section{قديرل الونن اللاري لالكلس:}

حدد الوزن الطري للكللس المستحدث من الاجزاء النباتية المزروعة بعدمرور 60 يوماً.

\section{النتلئج والمنالشة}

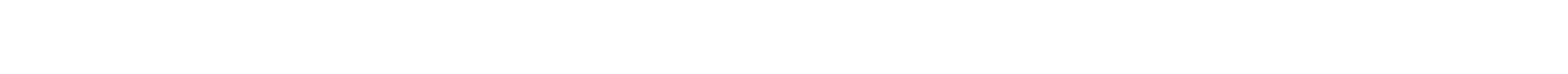
لستحداث ونمو الكالس من قطع بادرات Prosopis farcta النلمية على وسط MS الصلب الحاوي على الفهم المنظط (شكل A.2). تأثير NAA وBA في لستحدلث ونموكالس اللسقلن ولأوراق الفلفية لنبل الخرنوب النامية علم وس طا الصلب MS

لظٔهرت النتائج في الجدول (1) تباين لستحداث الكالس من قطع للسقلن والأوراق الفلقية لنبت الخرنوب

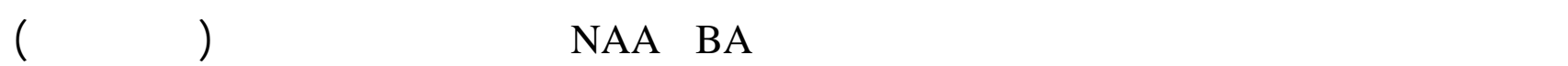

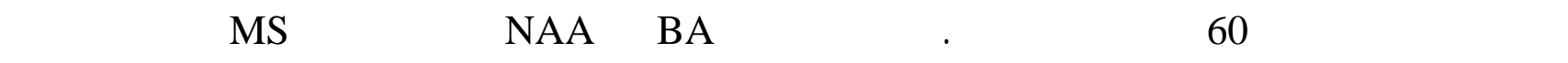

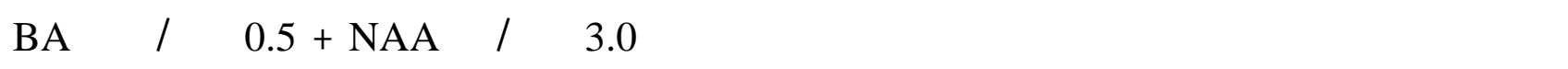

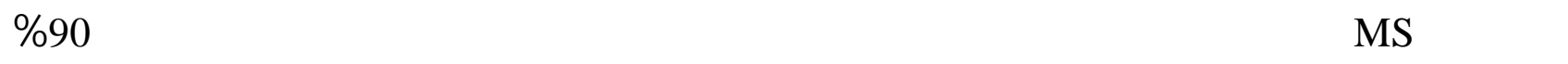

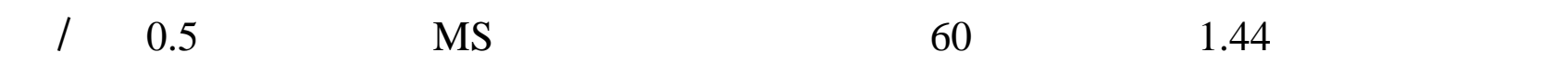

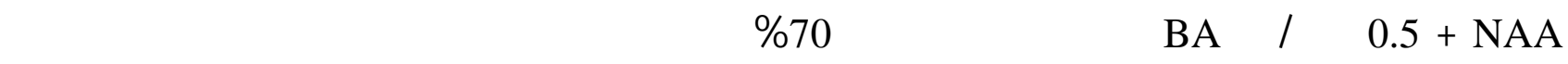

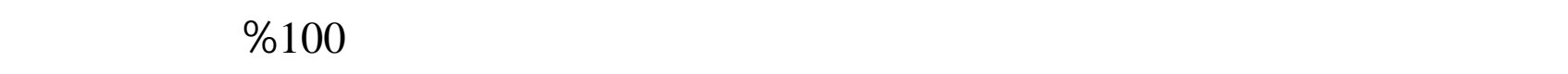

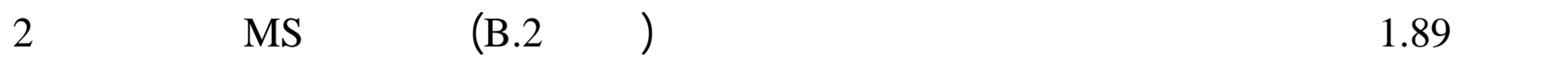
ملغم/لتر NAA + 0.5 ملغم/لتر BA.

وتباينت نسب اللستحداث في المعلملات الأخرى ولم قطر معلملة المقارنة وهي ونط MS

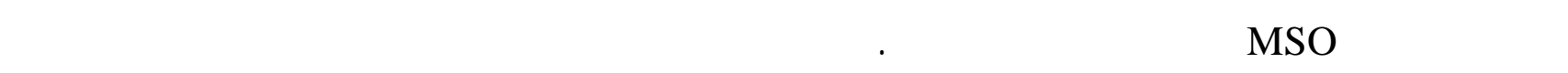
ولون الكاللس يعزى اللبب اله دورمظملت النمو وترلكيزها ونوع الجزء النباتي (الزيدي، 2009). 
رناطارق يحي و هناعسعيد الصالح

الجرل 1: تألثيرمظلمل النمو NAA وBA في الستحداث ونمو الكالام ن زراء ة ال عسقل ولاورق

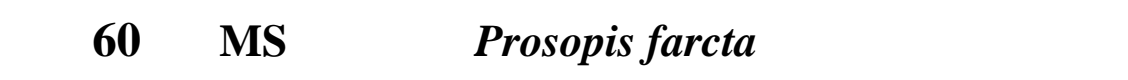

\begin{tabular}{|c|c|c|c|c|}
\hline \multicolumn{2}{|c|}{ قلع الورق الفلية } & \multicolumn{2}{|c|}{ قالع السيقلن } & \multirow{2}{*}{ الومط الغذائي } \\
\hline نسبة الستحداث & $\begin{array}{c}\text { الون المر) } \\
\text { (غلري }\end{array}$ & نسبة الستحداث & $\begin{array}{c}\text { الوزن الالري) } \\
\text { (غم) }\end{array}$ & \\
\hline 20 & 0.4 & 10 & 0.42 & MSO (control) \\
\hline 20 & 0.5 & 15 & 0.6 & $\mathrm{MS}+0.5 \mathrm{NAA}$ \\
\hline- & $*$ & - & $*$ & $\mathrm{MS}+1.0 \mathrm{NAA}$ \\
\hline- & $*$ & - & $*$ & $\mathrm{MS}+2.0 \mathrm{NAA}$ \\
\hline- & * & 15 & 0.4 & MS+3.0 NAA \\
\hline- & $*$ & - & $*$ & $\mathrm{MS}+0.5 \mathrm{BA}$ \\
\hline- & $*$ & - & $*$ & $\mathrm{MS}+1.0 \mathrm{BA}$ \\
\hline 25 & 0.7 & - & $*$ & $\mathrm{MS}+2.0 \mathrm{BA}$ \\
\hline 100 & 1.89 & 70 & 1.2 & $\mathrm{MS}+0.5 \mathrm{NAA}+0.5 \mathrm{BA}$ \\
\hline 50 & 0.9 & - & $*$ & $\mathrm{MS}+0.5 \mathrm{NAA}+1.0 \mathrm{BA}$ \\
\hline- & * & - & $*$ & $\mathrm{MS}+0.5 \mathrm{NAA}+2.0 \mathrm{BA}$ \\
\hline 90 & 1.2 & 20 & 0.7 & $\mathrm{MS}+1.0 \mathrm{NAA}+0.5 \mathrm{BA}$ \\
\hline 90 & 1.2 & 15 & 0.5 & $\mathrm{MS}+1.0 \mathrm{NAA}+1.0 \mathrm{BA}$ \\
\hline 40 & 0.8 & 15 & 0.6 & $\mathrm{MS}+1.0 \mathrm{NAA}+2.0 \mathrm{BA}$ \\
\hline 90 & 1.75 & 50 & 0.92 & $\mathrm{MS}+2.0 \mathrm{NAA}+0.5 \mathrm{BA}$ \\
\hline 30 & 0.8 & - & $*$ & $\mathrm{MS}+2.0 \mathrm{NAA}+1.0 \mathrm{BA}$ \\
\hline 20 & 0.4 & 20 & 0.4 & $\mathrm{MS}+2.0 \mathrm{NAA}+2.0 \mathrm{BA}$ \\
\hline 90 & 1.62 & 90 & 1.44 & $\mathrm{MS}+3.0 \mathrm{NAA}+0.5 \mathrm{BA}$ \\
\hline 10 & 0.4 & 20 & 0.4 & $\mathrm{MS}+3.0 \mathrm{NAA}+1.0 \mathrm{BA}$ \\
\hline- & $*$ & - & $*$ & $\mathrm{MS}+3.0 \mathrm{NAA}+2.0 \mathrm{BA}$ \\
\hline
\end{tabular}

* انفاخ التطعة النباتية دون تكوين كللس وادت فيما بعد اللى موت التطعة النباتية القيم الوارة في الجدول جميعها تمل معل كثل كثرة مكررات

قد يفسر قفوق قطع الأوراق الفلقية على للسقان في لستحداث الكالس إلى لحتواء لُٔسجة الأوراق الفلقية

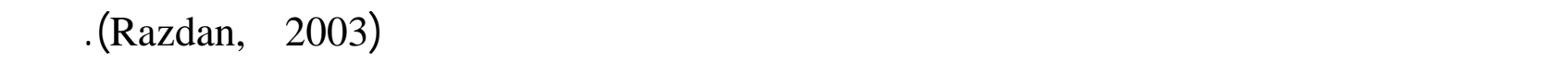

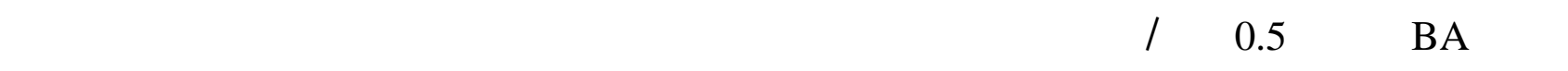

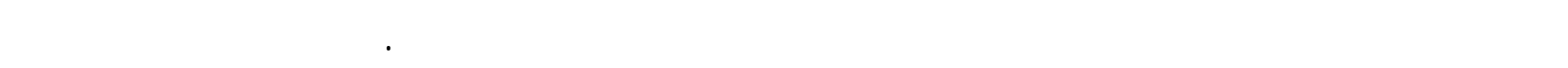

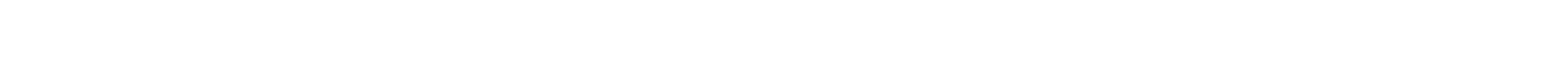
للازراعة النسيجية (Vijay et al., 2010). 


\section{تأثير IBA وBAف الستحدث ونموكالس السقلن ولأوراق الغلفية لنبل الخرنوب النامية علل وصا}

الصلب MS

يبين الجدول (2) أن إضلفة ترلكيز IBA وBA بصورة مففرة إلى وسط MS الصلبشجع + صورة قليلة لستحداث الكاللس من قطع السيقلن والأوراق الفلقية بعد مرور 60 يوماً من الزراعة .

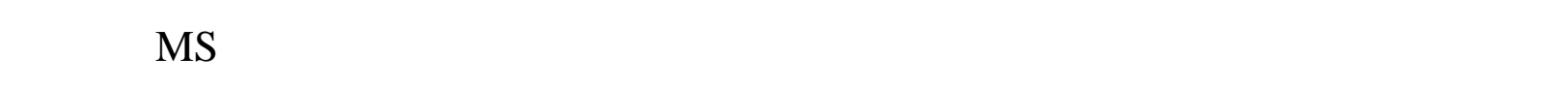

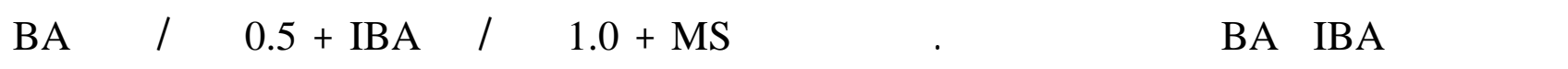

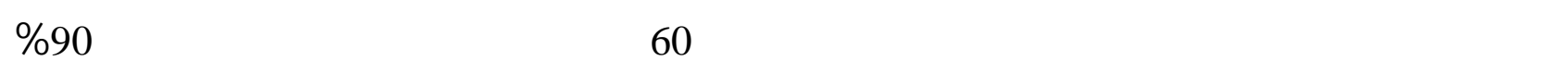

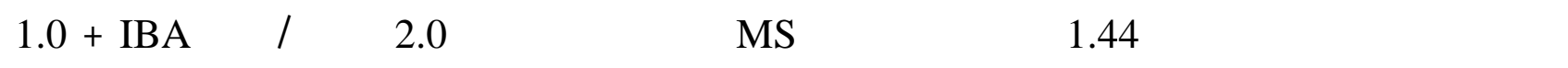

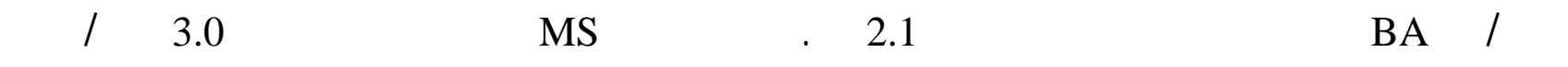

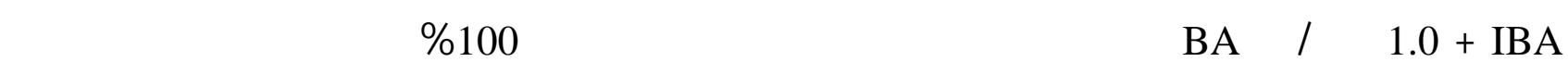

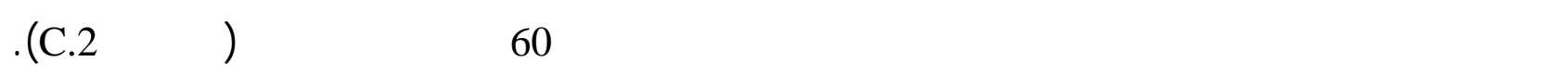

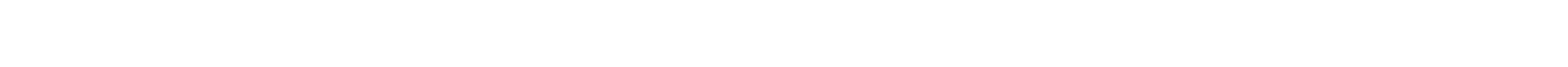

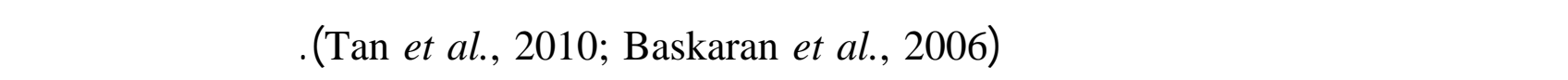

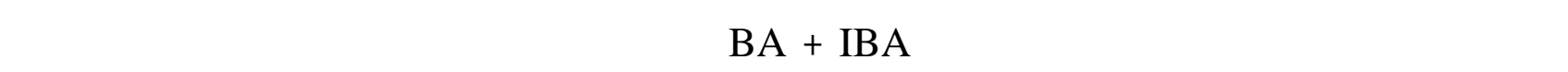

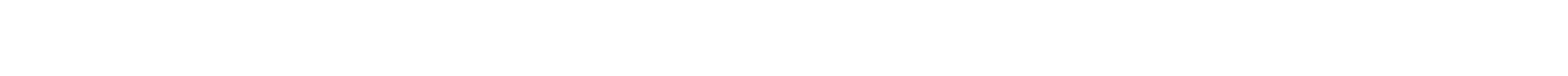
(Barriobero et al., 1995) 
رناطارق يحي و هناعسعيد الصالح

الجرل 2: تأثيرمظلملت النمو IBA وBAفي الستحداث ونمو الكالسمن زراعة اللسقلن ولاورق الفلفية

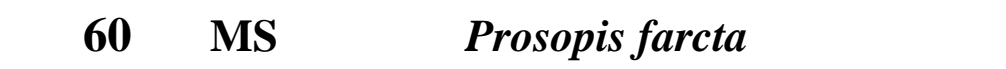

\begin{tabular}{|c|c|c|c|c|}
\hline \multicolumn{2}{|c|}{ قاع الورل الdلفية } & \multicolumn{2}{|c|}{ قاع السيقل } & \multirow{2}{*}{ الوطمط الغذائي } \\
\hline الكالس (مبة الستحد) & $\begin{array}{c}\text { الونن الالري } \\
\text { (غم) }\end{array}$ & الكالس (\%) الستحدل & $\begin{array}{c}\text { الونن الالري } \\
\text { (غم) }\end{array}$ & \\
\hline 01 & 0.4 & 15 & 0.42 & MSO (control) \\
\hline - & $*$ & 01 & 0.83 & $\mathrm{MS}+0.5 \mathrm{IBA}$ \\
\hline- & * & 10 & 0.4 & MS+1.0 IBA \\
\hline 10 & 0.14 & - & * & MS+2.0 IBA \\
\hline 10 & 0.17 & 20 & 0.5 & MS+3.0 IBA \\
\hline- & $*$ & 10 & 0.6 & MS+0.5 BA \\
\hline 15 & 0.4 & 15 & 0.4 & $\mathrm{MS}+1.0 \mathrm{BA}$ \\
\hline 30 & 0.8 & 15 & 0.9 & $\mathrm{MS}+2.0 \mathrm{BA}$ \\
\hline 60 & 1.12 & 30 & 1.57 & $\mathrm{MS}+0.5 \mathrm{IBA}+0.5 \mathrm{BA}$ \\
\hline 60 & 1.48 & 80 & 1.02 & $\mathrm{MS}+0.5 \mathrm{IBA}+1.0 \mathrm{BA}$ \\
\hline 70 & 1.61 & 70 & 1.0 & $\mathrm{MS}+0.5 \mathrm{IBA}+2.0 \mathrm{BA}$ \\
\hline 90 & 2.12 & 90 & 1.44 & $\mathrm{MS}+1.0 \mathrm{IBA}+0.5 \mathrm{BA}$ \\
\hline 80 & 1.42 & 90 & 1.28 & $\mathrm{MS}+1.0 \mathrm{IBA}+1.0 \mathrm{BA}$ \\
\hline 70 & 1.2 & 80 & 1.73 & $\mathrm{MS}+1.0 \mathrm{IBA}+2.0 \mathrm{BA}$ \\
\hline 40 & 0.8 & 80 & 1.0 & $\mathrm{MS}+2.0 \mathrm{IBA}+0.5 \mathrm{BA}$ \\
\hline 70 & 1.7 & 90 & 2.1 & $\mathrm{MS}+2.0 \mathrm{IBA}+1.0 \mathrm{BA}$ \\
\hline 15 & 0.7 & 20 & 0.6 & $\mathrm{MS}+2.0 \mathrm{IBA}+2.0 \mathrm{BA}$ \\
\hline 80 & 1.1 & 50 & 0.84 & $\mathrm{MS}+3.0 \mathrm{IBA}+0.5 \mathrm{BA}$ \\
\hline 100 & 2.42 & 70 & 1.02 & $\mathrm{MS}+3.0 \mathrm{IBA}+1.0 \mathrm{BA}$ \\
\hline 15 & 0.76 & 30 & 0.7 & $\mathrm{MS}+3.0 \mathrm{IBA}+2.0 \mathrm{BA}$ \\
\hline
\end{tabular}

* انفاخ التطعة النباتية دون تكوين كاللس وادت فيما بعد اللى موت التطعة النباتية

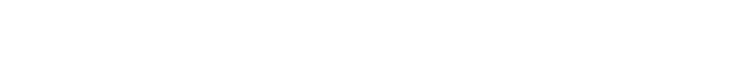

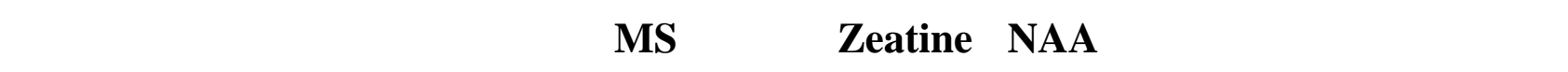
والأوراق الفلفية لنبل الخرنوب النامية علل وضما MS

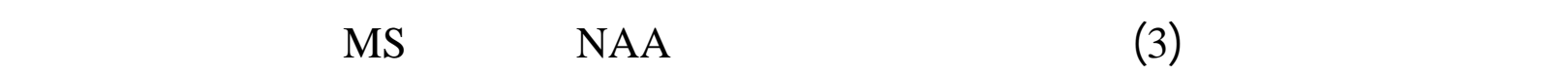
قليلة لستحداث الكالل من قطع للسقان والأوراق الفلقية في حن أن وجود Zeatine لوحهد في وس طس ط

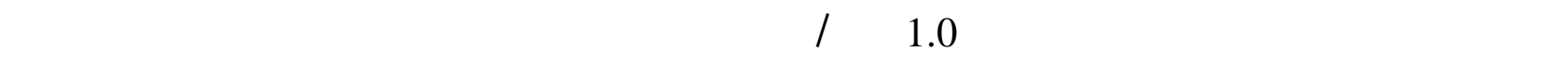

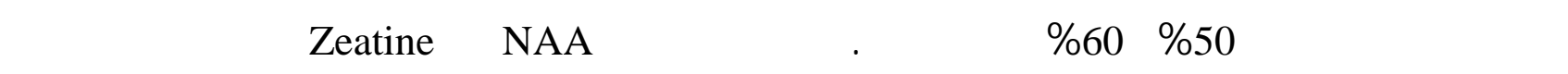

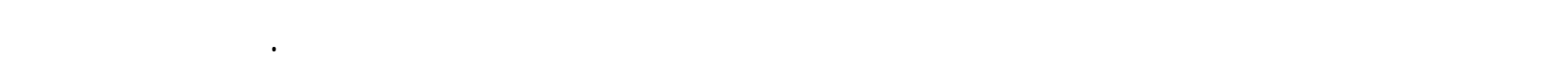

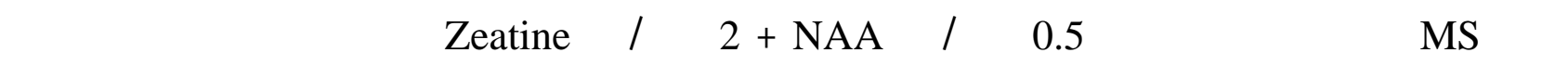


الكالس 90\% وبذات الوقت وهو الأكفأ في دعم نمو إذ بلغ معدل الوزن الطري 2.17 غم بع دـه -رور 60

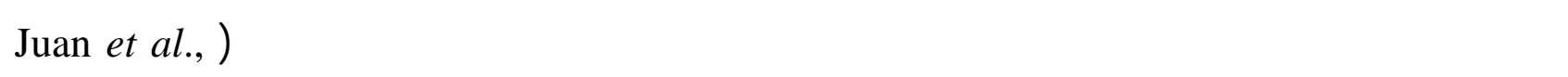
2010) وبسب تدلخل الاوكسين مع للسايتوكاينين.

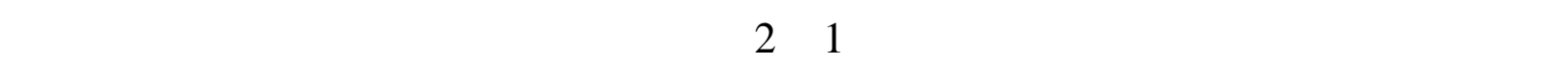

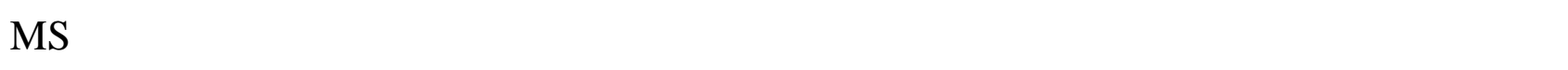

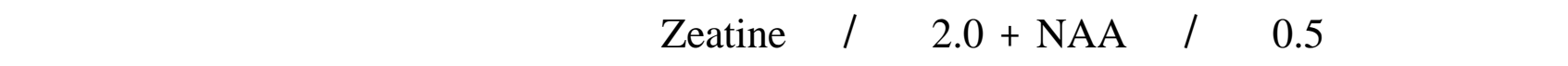

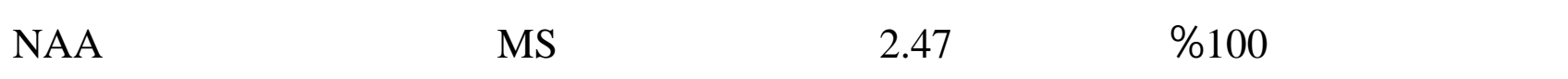

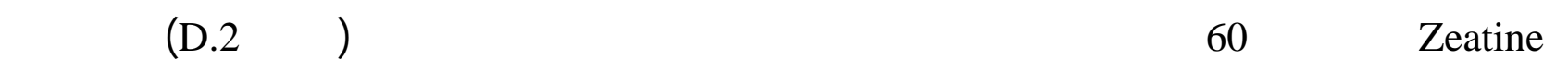

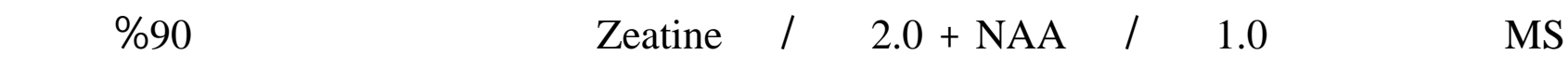
دعمه لنمو الكالس إذ بلغ معدل وزنه الطاري 2.32 غم.

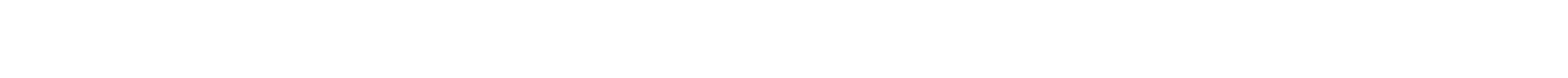

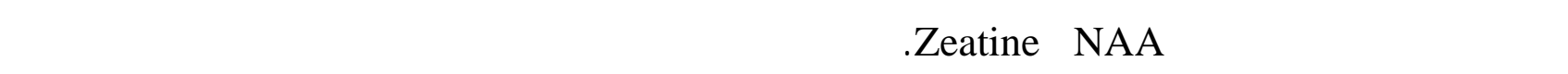

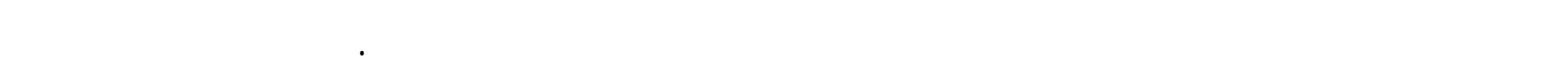

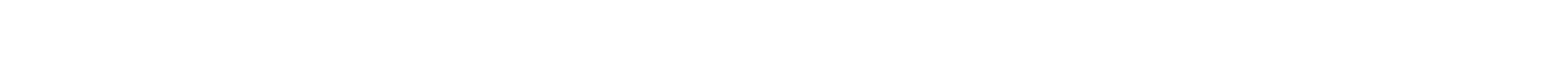
يتكون ذو لون بني او غلمق (Chaudhry et al., 2007). 
رناطارق يحي و هناعسعيد الصالح

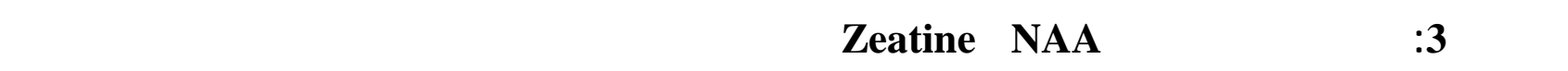
الفلفية لنبلت الخرنوب Prosopis farcta عل وصط MS بs 60 يوماً

\begin{tabular}{|c|c|c|c|c|}
\hline \multicolumn{2}{|c|}{ قلع الورف الفلية } & \multicolumn{2}{|c|}{ قاع السقلن } & \multirow{2}{*}{ الومط الغذائي } \\
\hline نسبة لستحدلث & $\begin{array}{c}\text { الونن اللري } \\
\text { (غم) }\end{array}$ & الكسبة لمستحداث & $\begin{array}{c}\text { الون الالري) } \\
\text { (غم) }\end{array}$ & \\
\hline 15 & 0.42 & 01 & 0.46 & MSO (control) \\
\hline 02 & 0.52 & 01 & 0.57 & $\mathrm{MS}+0.5 \mathrm{NAA}$ \\
\hline- & $*$ & - & $*$ & $\mathrm{MS}+1.0 \mathrm{NAA}$ \\
\hline 02 & 0.41 & 01 & 0.4 & $\mathrm{MS}+2.0 \mathrm{NAA}$ \\
\hline- & $*$ & - & $*$ & $\mathrm{MS}+3.0 \mathrm{NAA}$ \\
\hline 50 & 0.91 & 15 & 0.69 & MS+0.5 Z \\
\hline 60 & 0.69 & 50 & 0.66 & $\mathrm{MS}+1.0 \mathrm{Z}$ \\
\hline- & $*$ & 01 & 0.15 & $\mathrm{MS}+2.0 \mathrm{Z}$ \\
\hline 70 & 1.49 & 70 & 1.27 & $\mathrm{MS}+0.5 \mathrm{NAA}+0.5 \mathrm{Z}$ \\
\hline 70 & 1.37 & 30 & 0.7 & $\mathrm{MS}+0.5 \mathrm{NAA}+1.0 \mathrm{Z}$ \\
\hline 100 & 2.47 & 90 & 2.17 & $\mathrm{MS}+0.5 \mathrm{NAA}+2.0 \mathrm{Z}$ \\
\hline 80 & 1.42 & 70 & 1.31 & $\mathrm{MS}+1.0 \mathrm{NAA}+0.5 \mathrm{Z}$ \\
\hline 90 & 2.14 & 80 & 1.3 & $\mathrm{MS}+1.0 \mathrm{NAA}+1.0 \mathrm{Z}$ \\
\hline 90 & 2.32 & 70 & 1.74 & $\mathrm{MS}+1.0 \mathrm{NAA}+2.0 \mathrm{Z}$ \\
\hline 80 & 1.78 & 70 & 1.53 & $\mathrm{MS}+2.0 \mathrm{NAA}+0.5 \mathrm{Z}$ \\
\hline 80 & 1.1 & 30 & 0.63 & $\mathrm{MS}+2.0 \mathrm{NAA}+1.0 \mathrm{Z}$ \\
\hline 70 & 1.7 & 70 & 0.61 & $\mathrm{MS}+2.0 \mathrm{NAA}+2.0 \mathrm{Z}$ \\
\hline 90 & 1.7 & 70 & 1.3 & $\mathrm{MS}+3.0 \mathrm{NAA}+0.5 \mathrm{Z}$ \\
\hline 90 & 2.1 & 70 & 1.42 & $\mathrm{MS}+3.0 \mathrm{NAA}+1.0 \mathrm{Z}$ \\
\hline 80 & 1.28 & 70 & 1.47 & $\mathrm{MS}+3.0 \mathrm{NAA}+2.0 \mathrm{Z}$ \\
\hline
\end{tabular}

* النفاخ التطعة النباتية دون تكوين كللس وادت فيما بعد اللى موت التطعة النباتية

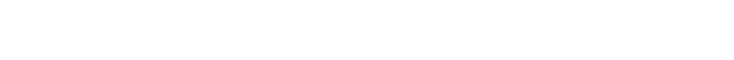

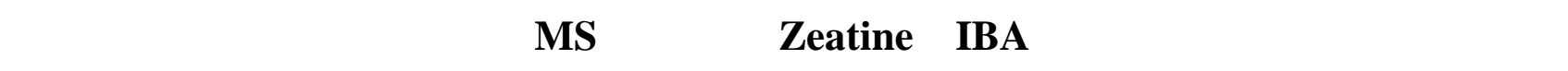

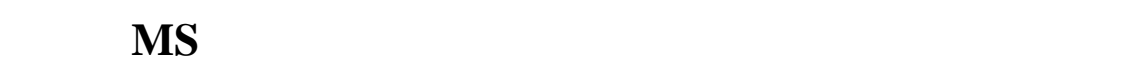

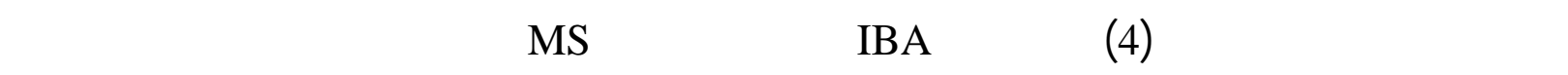

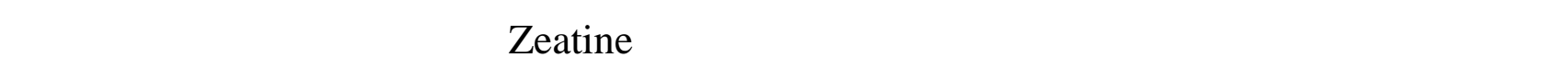

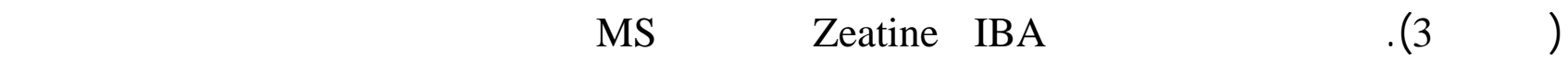

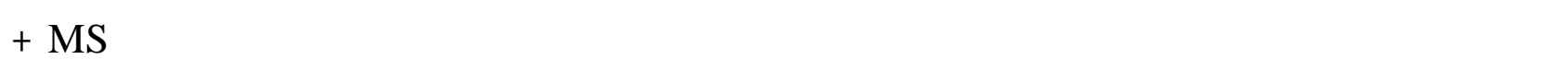

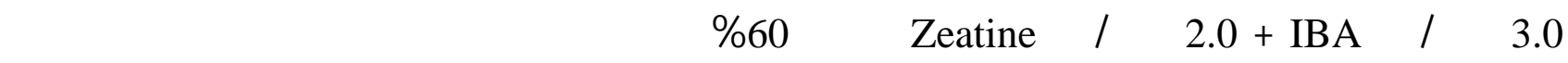

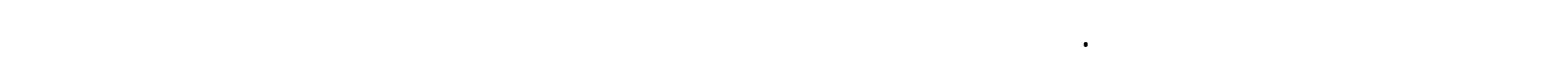

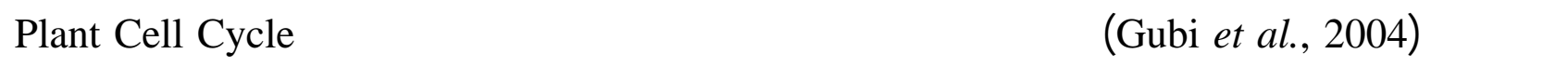


التي تتأثر غالباً بوجود النوعين من مظملت النمو الاوك سينت وال سايتوكاينينت ف ي الوس ط الغ ذائي .(George, 2008) وعلى عكس ذلكشجع هذا التدلخل بين الترلكيز المختلفة لل ـ IBA وZeatine لستحداث الك الس م ـن

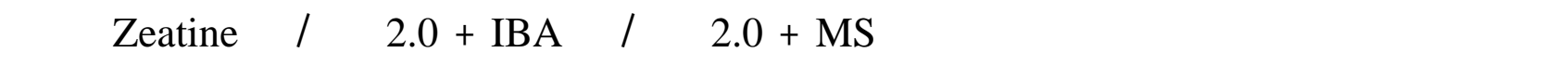
غيره من الأوسط في لستحداثه للكاللس بدلالة نسبة لمتحداثه البالغة 100\% وهو فغس الوسط الأمل لنمو هذا

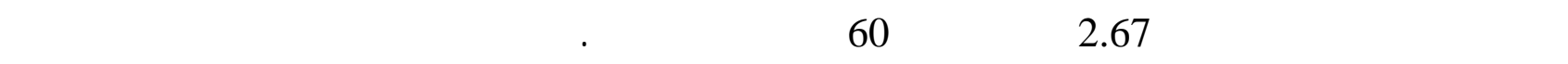

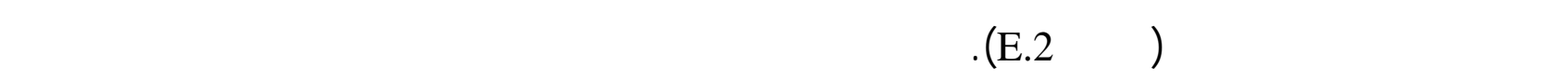

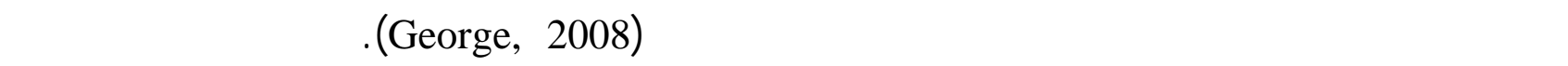
الموازنة بين مظملت النمو في الوسط الغذائي مما يتسب عن زياة لمتصاص مظملت النمو بالاعتماد على الموازنة بين للشحنات الموجبة وللسالبة علىطرفي الغثاء الخلوي وبالتالي زيادة لمتصاص مظملت النماص النم -و الأخرى والارفاع بمستوى البناء الحيوي مما يؤدي إلى زياة في بناء البروتين والاقتسلم الخلوي وبالت اللي زيادة الوزن الطري (Juan et al., 2010; Gubi et al., 2004). 
رناطارق يحي و هناعسعيد الصالح

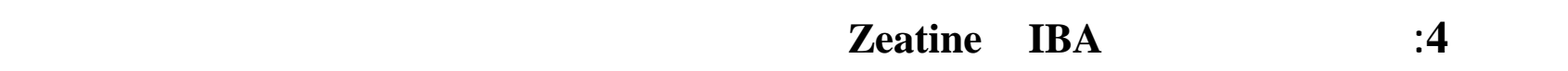

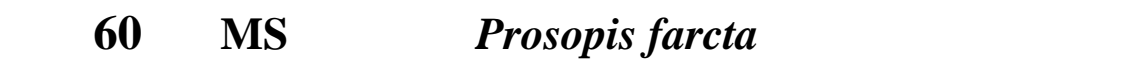

\begin{tabular}{|c|c|c|c|c|}
\hline \multicolumn{2}{|c|}{ قاع الورق الفلية } & \multicolumn{2}{|c|}{ قالع السيقل } & \multirow{2}{*}{ الومل الغذأي } \\
\hline الكسبة الستحداث & $\begin{array}{c}\text { الون اللاري } \\
\text { (غم) }\end{array}$ & اكسبة الستحداث & $\begin{array}{c}\text { الون الاري } \\
\text { (غم) }\end{array}$ & \\
\hline 15 & 0.4 & 15 & 0.5 & MSO (control) \\
\hline- & * & 20 & 0.57 & MS+0.5 IBA \\
\hline- & $*$ & - & * & $\mathrm{MS}+1.0 \mathrm{IBA}$ \\
\hline- & $*$ & 20 & 0.41 & MS+2.0 IBA \\
\hline- & * & - & * & $\mathrm{MS}+3.0 \mathrm{IBA}$ \\
\hline 50 & 0.8 & 30 & 0.63 & $\mathrm{MS}+0.5 \mathrm{Z}$ \\
\hline 50 & 0.67 & 50 & 0.65 & $\mathrm{MS}+1.0 \mathrm{Z}$ \\
\hline- & $*$ & - & $*$ & $\mathrm{MS}+2.0 \mathrm{Z}$ \\
\hline 40 & 1.07 & - & * & $\mathrm{MS}+0.5 \mathrm{IBA}+0.5 \mathrm{Z}$ \\
\hline 60 & 1.1 & 15 & 0.56 & $\mathrm{MS}+0.5 \mathrm{IBA}+1.0 \mathrm{Z}$ \\
\hline 30 & 0.88 & - & $*$ & $\mathrm{MS}+0.5 \mathrm{IBA}+2.0 \mathrm{Z}$ \\
\hline 70 & 1.48 & 20 & 0.76 & $\mathrm{MS}+1.0 \mathrm{IBA}+0.5 \mathrm{Z}$ \\
\hline 80 & 2.31 & - & * & $\mathrm{MS}+1.0 \mathrm{IBA}+1.0 \mathrm{Z}$ \\
\hline 90 & 2.1 & 20 & 0.7 & $\mathrm{MS}+1.0 \mathrm{IBA}+2.0 \mathrm{Z}$ \\
\hline 40 & 0.85 & - & * & $\mathrm{MS}+2.0 \mathrm{IBA}+0.5 \mathrm{Z}$ \\
\hline 90 & 2.34 & - & * & $\mathrm{MS}+2.0 \mathrm{IBA}+1.0 \mathrm{Z}$ \\
\hline 100 & 2.67 & 30 & 0.65 & $\mathrm{MS}+2.0 \mathrm{IBA}+2.0 \mathrm{Z}$ \\
\hline 90 & 2.13 & 15 & 0.49 & $\mathrm{MS}+3.0 \mathrm{IBA}+0.5 \mathrm{Z}$ \\
\hline 80 & 1.11 & 15 & 0.48 & $\mathrm{MS}+3.0 \mathrm{IBA}+1.0 \mathrm{Z}$ \\
\hline 90 & 1.86 & 60 & 0.9 & $\mathrm{MS}+3.0 \mathrm{IBA}+2.0 \mathrm{Z}$ \\
\hline
\end{tabular}

* النفاخ التطعة النباتية دون تكوين كاللس وادت فيما بعد اللى موت التطعة النباتية القيم الوارة في الجدول جميعها تمل معدل عثرة مكررات 


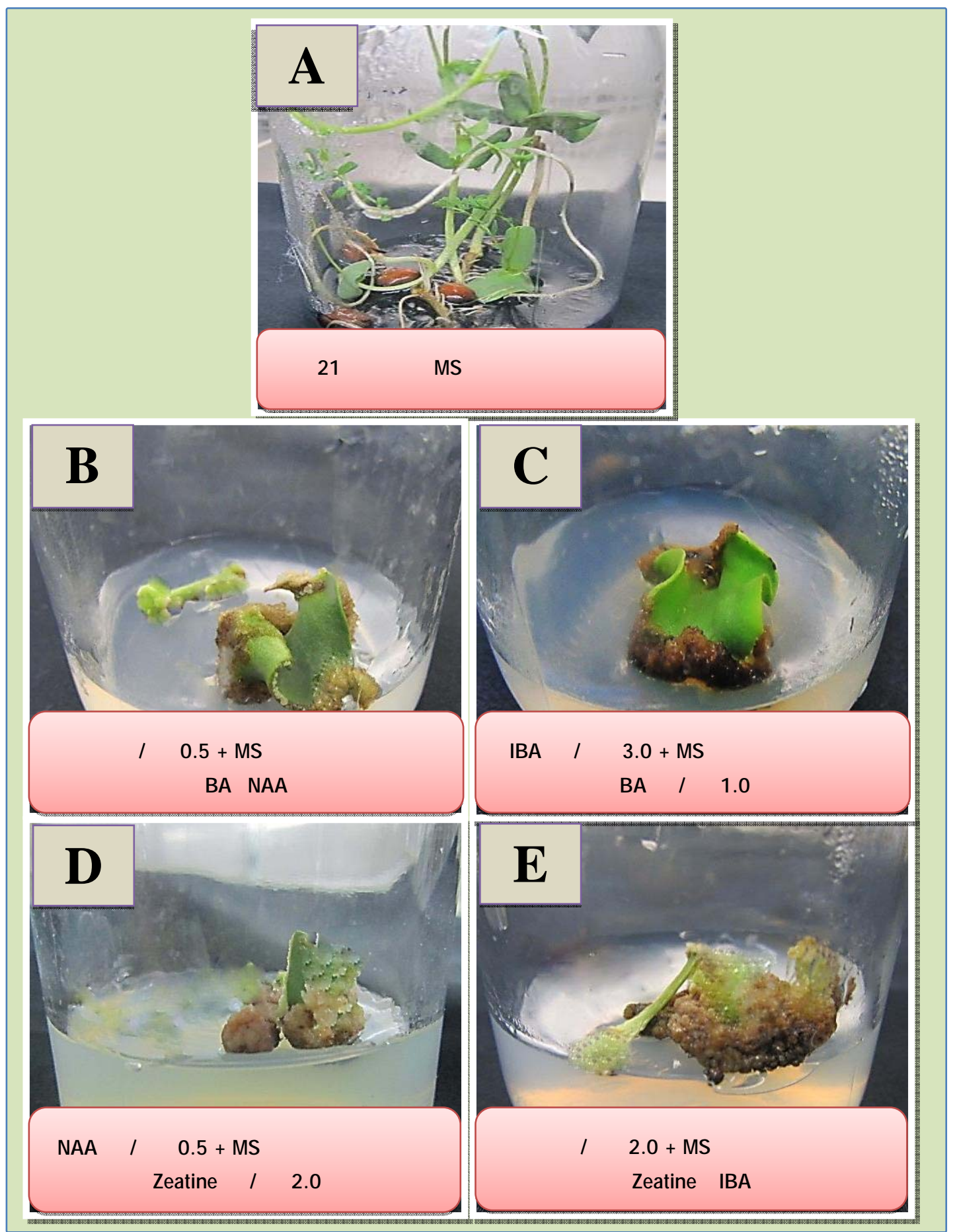

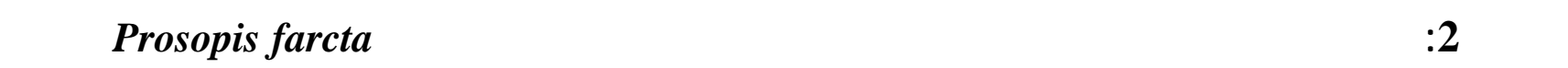

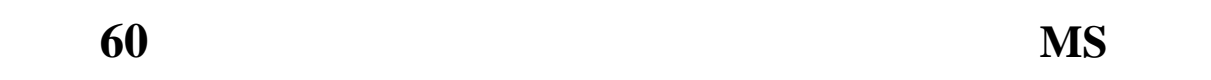




\section{رناطارق يحي و هناعسعيد الصالح

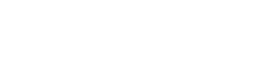

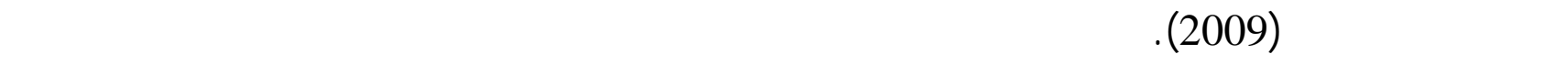
الثب لوحله او للثب مع البولي الكتروليت الصناعي LT-22 في ازالة عكورة الماء.مجلة هنهسة

$$
\text { الرافين، 17، } 28 \text {-36. }
$$

الجواري،سهلة محمد زيدانشعيب (2004). الزراعة المرافقة للمعلقت الخلوية المشقة من كالس اللسقان

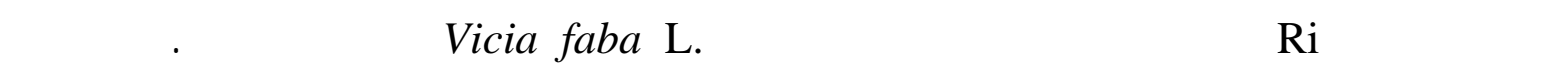

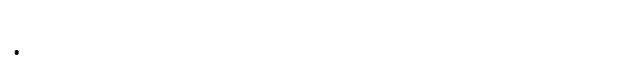

الزيدي، رغد نوف جرجسيس (2009). الزراعة النسيجية لنباتت الكرفس .Apium graveolens L خارج الجماج

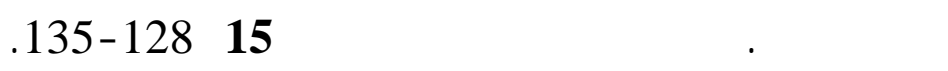

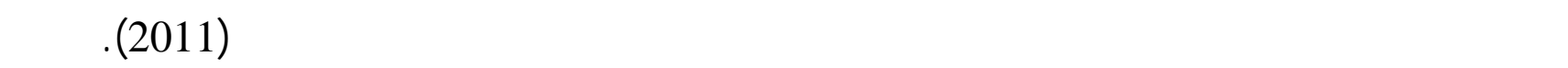

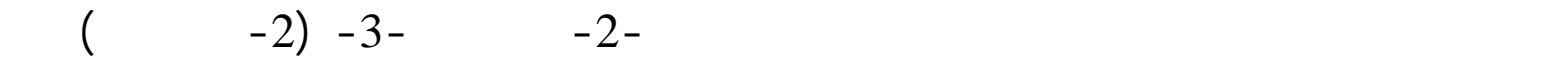

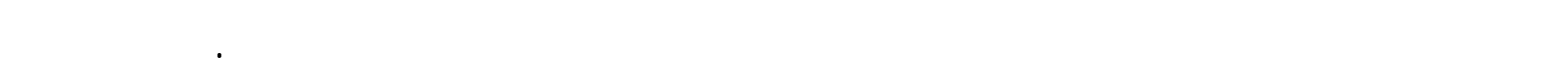
البصرة (العلميت)، 37، 134 -155. محمد، عبدالطلب سيد؛ عمر، مبشر صالح (1990). المفاهيم الرئيسة في زراعة الخلايا والأنسجة والأعضاء للنبلت. مطبعة جلمعة الموصل، العراق.

\section{المصاكر الأجنبية}

Asadollahi, K.; Abassi, N.; Afshar, N.; Alipour, M.; Asadollahi, P. (2010). Investigation of the effects of Prosopis farcta plant extract on Rat's aorta. J. Medici. Plants Res., 4,142-147.

Barriobero, C.I.; Villalobos, N.; Guerra, H. (1995). Changes in protein and carbohydrate during the induction of callus from cotyledons of Cicer arieetinum $L$. the role of 2,4-D. Acta. Physiol. Plant., 17, 301-308.

Baskaran, P.P.; Rajeswari, B.; Jayabalan, N. (2006). Development of an in vitro regeneration system in sorghum (Sorghum bicolor (L.) Moench] using root transverse thin cell layers (tTCLs). Turk. J. Bot., 30, 1-9.

Chaudhry, Z.; Afroz, A.; Rashed, H. (2007). Effect of variety and plant growth regulators on callus proliferation and regeneration response of three tomato cultivars (Lycopersicon esculentum). Pak. J. Bot., 39, 857-869.

George, E.F.; Hall, A.; Klerk, G.D. (2008). "Plant Propagation by Tissue Culture". 3ed edn. Vol. 1, Springer, Dordrecht, Netherlands.

Gubi, J.; Lajchovav, Z.; Faragó. J.; Jurekovae, Z. (2004). Effect of growth regulators on shoot induction and plant regeneration in tomato (Lycopersicon esculentum Mill). Bio. Bratislava., 59, 405 -408.

http://www. alsirhan.com 
Humberto, F.H.F.; Causin, T.; Rufty, W.T.W.; James, F.J.F. (2010). Gas exchange and carbon metabolism in two Prosopis species (Fabaceae) from semiarid habitats: effects of elevated $\mathrm{Co}_{2}, \mathrm{~N}$ supply, and N source. Americ. J. Bot., 93,716-723.

Juan , L.; Lihua, W.; Jing, L.; Junhui, W. (2010). Effect of different plant growth regulators on callus induction in Catalpa bungei. African J. Agri. Res., 5, 2699-2704.

Kumar, K.; Singh, N. (2009). Micropropagation of Prosopis cineraria (L.) druce-A multipurpose desert tree. Res., 1,28-32.

Murashige, T.; Skoog, F. (1962). A revised medium for rapid growth and bioassay with tobacco tissue culture. Physiol. Plant., 15, 473-479.

Neumann, K.; Kumar, A.; Imani, J. (2009). "Plant Cell and Tissue Culture - A tool in Biotechnology". Springer, Berlin, Germany.

Omidi, A.; Ansari nik, H.; Ghazaghi, M. (2012). Prosopis farcta beans increase HDL cholesterol and decrease LDL cholesterol in ostriches (Struthio camelus).Trop. Anim. Health Prod., 45, 431-434.

Razdan, M. K. (2003). "Introduction to Plant Tissue Culture". 2ed edn. Enfield, NH, oxford, UK.

Sultana, R.S.; Bari, M.A. (2003). Effect of different plant growth regulators on direct regeneration of watermelon Citrus lanatus thumb. Plant Tiss. Cult. , 2, 173-177.

Tan, S.H.; Musa, R.; Ariff, A. ; Maziah, M. (2010). Effect of Plant Growth Regulators on Callus, Cell Suspension and Cell Line Selection for Flavonoid Production from Pegaga (Centella asiatica L. urban). American J. Biochem. Biotech., 6, 284-299.

Vijay, S.; Virk, G.S.; Nagpal, A. (2010). Effect of Explant Type and Different Plant Growth Regulators on Callus Induction and Plantlet Regeneration in Citrus jambhiri Lush. Environ. J. Sci. Tech., 5, 97-106. 